\title{
Correction to: Optical characterization of SiC films grown on $\mathrm{Si}(111)$
}

\author{
Raghavendra Rao Juluri ${ }^{1}$ John Lundsgaard Hansen ${ }^{1,2}$ - Peter Kjær Kristensen ${ }^{3}$ - Brian Julsgaard ${ }^{1,2}$. \\ Kjeld Pedersen ${ }^{3}$ (D)
}

Published online: 20 August 2019

(c) Springer-Verlag GmbH Germany, part of Springer Nature 2019

\section{Correction to: Applied Physics B (2018) 124:2 \\ https://doi.org/10.1007/s00340-018-7103-x}

Unfortunately, the first author name was incorrectly published in the original publication. The complete correct name is given below.

Raghavendra Rao Juluri

2 Department of Physics and Astronomy, Aarhus University, Ny Munkegade 120, 8000 Aarhus C, Denmark

3 Department of Materials and Production, Aalborg University, Skjernvej 4A, 9220 Aalborg Øst, Denmark 